\title{
Self-knowledge, Perception, and Margaret Cavendish's Metaphysics of the Individual
}

\author{
Laura Georgescu \\ Faculty of Philosophy, University of Groningen, Groningen, The Netherlands \\ L.Georgescu@rug.nl
}

\begin{abstract}
For Margaret Cavendish, every single part of matter has self-knowledge, and almost every part has perceptive knowledge. This paper asks what is at stake for Cavendish in ascribing self-knowing and perceptive properties to matter. Whereas many commentators take perception and self-knowledge to be guides to Cavendish's epistemology, this paper takes them to be guides to her metaphysics, in that it shows that these categories account for individual specificity and for relationality. A part of matter is a unique individual insofar as it is self-knowing - and it is a part in relation to other parts, and to the whole of matter, insofar as it is a perceptive part. This is so because self-knowledge is purely self-referential and complete, while perceptive knowledge is purely relational.
\end{abstract}

\section{Keywords}

Margaret Cavendish - perception - self-knowledge - metaphysics

Margaret Cavendish is a materialist: humans, minerals, sounds, colors, light, ideas, and minds are material bodies. Whatever is material is also natural, and, if anything is immaterial, it must be supernatural. ${ }^{1}$ She is adamant that the

1 Cavendish tends to use 'nature' and 'matter' to refer to both the parts of Nature/Matter, and Nature/Matter as a whole. In this paper, I often use capitalized versions to emphasize that these are technical terms. I use the following abbreviations for Cavendish's works: PPO: Philosophical and Physical Opinions (London, 1655; second, substantially revised edition 1663); PL: Philosophical Letters (London, 1664); OE P: Observations upon Experimental Philosophy 
radical difference between material and immaterial makes it impossible for them to causally interact. What follows is that the only principle available to explain natural phenomena, and the different properties of bodies, are Matter and its properties. ${ }^{2}$ Matter comes in three "degrees": rational, sensitive, and inanimate. ${ }^{3}$ The first two are self-moving, while the inanimate parts are not, being instead moved by sensitive matter. ${ }^{4}$ She sometimes refers to the rational, the sensitive and the inanimate, as the constitutive parts of Matter, in contrast with the effective parts of matter (the sensible, concrete bodies or creatures). ${ }^{5}$ It follows that, in a sense, matter is constitutively heterogenous, since, however small a body one considers, it will be a blend of inanimate, sensitive, and rational material parts. A way to understand this is to treat the effective parts of matter (the concrete, physical bodies) as mixed bodies, and the constitutive parts as the principles (or grounds) of these mixtures, and not as integral parts of the effective parts. ${ }^{6}$ However much you dissect, say, a fly, or observe it

(London, 1666; second edition 1668); GN P: Grounds of Natural Philosophy (London, 1668). For citations, I used Margaret Cavendish, Observations upon Experimental Philosophy, ed. Eileen O'Neill (Cambridge, 2001) and the second revised version of the PPO.

2 On Cavendish's materialism, see Stewart Duncan, "Debating Materialism: Cavendish, Hobbes, and More," History of Philosophy Quarterly, 29 (2012), 391-409; idem, "Materialism and the Activity of Matter in Seventeenth-Century European Philosophy," Philosophy Compass, 11 (2016), 671-68o. On the role of her materialism in her politics, see Lisa Sarasohn, The Natural Philosophy of Margaret Cavendish (Baltimore, MD, 2010), especially chs. 5 and 6.

3 See, e.g., PPO 2; OEP 16; GNP 3.

4 Cavendish uses "animate" and "inanimate" to distinguish between self-moving and non-self moving matter, not between living and non-living. On this point, see, e.g., OEP 112. For instance, she claims that "all the parts of Nature have Life [...] but, all the parts have not active Life" (GNP 7). Sensible bodies and the self-moving parts have active life, while the inanimate has an inactive life. It seems that Cavendish uses "life" for anything that is existent: if something exists, then it is alive.

5 For her distinction between effective and constitutive parts, see OEP 13, 25, 27-28, 161. Following Cavendish, I use "sensible body," "creature" and "effective part" interchangeably. At PL 433, Cavendish writes: "That Infinite Nature is but one Infinite body, divided into Infinite parts, which we call Creature; [...]." Each "effective part" is a "creature": chemical elements, vegetables, livers, humans, etc., are all creatures.

6 Cavendish's theory of the constitution of matter - also known as the theory of degrees of matter or the doctrine of complete blending - is a later development. In her early works, Cavendish defended atomism, but rejected it from PPO onwards. On Cavendish's endorsement of atomism, see Jay Stevenson, "The Mechanist-Vitalist Soul of Margaret Cavendish," Studies in English Literature, 36 (1996), 527-543. Stephen Clucas, "The Duchess and the Viscountess: Negotiations between Mechanism and Vitalism in the Natural Philosophies of Margaret Cavendish and Anne Conway," In-Between: Essays and Studies in Literary Criticism, 9 (2000), 125-136, argues that, while Cavendish rejects atomic mechanism, ultimately her complete blending theory is compatible with vital atomism. Against Clucas, Detlefsen argues that Cavendish's arguments work also against vital atomism; see Karen Detlefsen, "Atomism, 
through a microscope (irrespective of how powerful the microscope), you will never get to the constitutive parts. If so, for Cavendish, there are no foundational compositional building blocks out of which the sensible bodies are composed, as one might treat Cartesian corpuscles or Epicurean atoms. This is because an effective part does not bottom out compositionally into the constitutive parts: the constitutive parts and the effective parts are related as a cause to its effect. Thus, they are related not compositionally, but causally. Concrete bodies are characterized rather by what they do to other bodies, and not what they are made up of. ${ }^{7}$

Cavendishian Matter (as a whole) has other properties beyond its blended make-up: it is alive, self-moving, eternal in duration, and infinite in magnitude as well as in its number of parts. In the mature works of Cavendish, at least from OEP onwards, all parts of Matter, including the inanimate parts, are also of necessity self-knowing. ${ }^{8}$ Sensible bodies and the self-moving parts of matter are, in addition, perceptive, although the inanimate parts of matter most definitely are not. As we will see, Nature (qua the entirety of matter) does not have perception fundamentally, but at best derivatively through its effective parts, because perception is the effect of corporeal motions towards other external parts, and there are no such external parts to Matter itself. Perception simpliciter should not be conflated with animal sense perception, because perception is a fundamental property both of all sensible bodies and of the self-moving parts of matter. When Cavendish talks of perception without qualification, we

Monism, and Causation in the Natural Philosophy of Margaret Cavendish," in Daniel Garber and Steven Nadler, eds., Oxford Studies in Early Modern Philosophy, 3 (Oxford, 2006), 199-240. For a response to Detlefsen's treatment of Cavendish's rejection of atomism, see Jonathan Shaheen, "Part of Nature and Division in Margaret Cavendish's Materialism," Synthese, 196 (2019), 3551-3575. In the same paper, Shaheen covers complete blending in depth and argues that it is a contingent feature of Cavendish's world, and that Cavendish allows for the possibility of unmixed spatial regions. For different treatments of complete blending, see Eileen O'Neill, "Introduction," in OEP X-xxxvi (esp. xxxi-xxxii). In Catherine Wilson, "Two Opponents of Material Atomism: Cavendish and Leibniz," in Pauline Phemister and Stuart Brown, eds., Leibniz and the English-Speaking World (Dordrecht, 2007), 35-50, Wilson takes the doctrine of complete blending to be "obscure and arbitrary" (41). For a detailed analysis of the functions of complete blending in Cavendish's philosophy, see, e.g., Deborah Boyle, The Well-Ordered Universe: The Philosophy of Margaret Cavendish (Oxford, 2018).

7 For Cavendish, focusing on the (al)chemical composition, elemental composition or mechanical-physical composition of bodies is treating that body via the principles of one Art or another, rather than strictly following Nature's principles. To follow the latter would require first looking at what the capacities of that creature are while knowing that no natural knowledge of that creature's capacities can ever be complete if only because, necessarily, there will be other parts of Nature with which that creature cannot interact as per its finitude.

8 Cavendish did not always hold the view that the inanimate parts have knowledge (e.g., PL 99); she does from OEP onwards (e.g., OEP 39). 
should not understand it according to the model of animal perception. Animal perception is an instantiation of perception, not perception per se.

Given that Cavendish rejects mechanical accounts of change and the possibility of transfer between bodies, she appeals to the self-motion and perception of Matter in order to explain natural change and the apparent order (and disorder) in Nature. If I knock over a glass of water and the water spills, my hand knocking the glass does not determine the glass to fall, and the glass' falling does not determine the spilling of water. ${ }^{9}$ Instead, the glass falls by its own motion, and the water spills by its own motion. The motion of the glass is the effect of the glass itself - its own self-motion - as a response to its perception of my hand's knocking it. In Cavendish's own terms, my hand "occasions" the glass to fall. It does not cause it to move, but only to initiate its own motion as a result of perceiving my hand: it appears to know what to do as a result of its perceptive knowledge. But how does the glass perceive my hand? A common reading in the literature is that perception works by "patterning out": when I see the glass, the matter in my eye moves to imitate or copy the figure of the glass; when the glass perceives the hand, some analogous patterning out occurs. ${ }^{10}$

Cavendish indeed has plenty to say about bodies patterning out other bodies. But she also claims that,

[n] either can I certainly affirm, that all perception consists in patterning out exterior objects; for, although the perception of our human senses is made that way, yet nature's actions being so various, I dare not conclude from thence, that all perceptions of the infinitely various parts and figure of nature are made after the same manner. [...] Therefore it is absurd to confine all perception of nature, either to pressure and reaction, or to the animal kind of perception. ${ }^{11}$

Cavendish's strategy is to claim that perception is a necessary fundamental property of matter, but the exact ways in which bodies are sensible are

9 Whether Cavendish accepts determinism or not is beyond the scope of this paper. The literature is divided on this issue. For non-determinist readings, see Karen Detlefsen, "Reason and Freedom: Margaret Cavendish on the Order and Disorder of Nature," Archiv für Geschichte der Philosophie, 89 (2007), 157-191, and Boyle, The Well-Ordered Universe. For the opposite view, see for instance David Cunning, "Cavendish on Material Causation and Cognition," in Dominik Perler and Sebastian Bender, eds., Causation and Cognition in Early Modern Philosophy (New York, 2020), 145-170.

10 See, e.g., Susan James, "The Philosophical Innovations of Margaret Cavendish," British Journal for the History of Philosophy, 7 (1999), 219-244. OEP 140. 
unverifiable. And since there is no principled way of extrapolating from human perception to general perception, we cannot possibly know how other sensible bodies perceive, but because as humans we intimately know the way in which we perceive, we analogically use our human model of perception to grasp the ways in which other bodies perceive. ${ }^{12}$ Thus, there is likely no single particular way of perceiving. Perception as a fundamental action of matter grounds individual perceptive knowledges and ways of perceiving; the principle is, of course, not reducible to its particular instantiations, and patterning out should not be assumed to stand for all perception. ${ }^{13}$

If we take a mechanistic perspective, the trajectory of the glass's falling, and the speed at which it falls, seem to be explained fully by the pressure my hand and other surrounding surfaces exerted on the glass. But if the cause of the glass falling is the glass' own motions, we might well ask why the glass fell as it did. The dominant interpretative trend in the literature has been to try to kill two birds with one stone - seeking to explain the apparently regular behavior of bodies through their self-knowledge, and at the same time, in doing so, to explain what self-knowledge itself is. Michaelian is explicit on this: for Cavendish, "the self-knowledge of a thing includes knowledge of how to respond to the activity of external things." ${ }^{14}$ Boyle adds to this model divinely instituted norms of behavior. According to her account, the water decides to spill because it decides to follow a norm which is proper to the kind of body that it is: water is the kind of thing that is supposed to spill. Self-knowledge is normative in that it carries the knowledge of the norms a body must follow. ${ }^{15}$ So, on this reading, bodies know what to do, and what they should do, because they are self-knowing.

In this paper, I propose a different take on the role that self-knowledge and perception play in Cavendish's philosophy. My reading is this: fundamental perception pertains to the relationality between the parts of matter, while fundamental self-knowledge pertains to the individuality of each of these parts. In other words, qua part, matter perceives, and qua whole, it is self-knowing. Each and every part of matter is a true unity (or a whole), and therefore an

12 Cavendish makes this point clear in a few places in OEP; see OEP 14O, 169, 172, 207, 284.

13 See, e.g., OEP 139. For a discussion of how perception works and the various kinds of perceptions, see Kourken Michaelian, "Margaret Cavendish's Epistemology," British Journal for the History of Philosophy, 17 (2009), 31-53; Deborah Boyle, "Margaret Cavendish on Perception, Self-knowledge, and Probable Opinion," Philosophy Compass, 10 (2015), 438450; Marcus Adams, "Visual Perception as Patterning: Cavendish against Hobbes on Sensation," History of Philosophy Quarterly, 33 (2016), 193-214.

14 Michaelian, "Margaret Cavendish's Epistemology," 46. Adams, "Visual Perception as Patterning," adopts the same reading.

On Boyle's account of self-knowledge see The Well-Ordered Universe, 105-112. 
individual - and not just a fleeting composition of corporeal motions - insofar as each is self-knowing. ${ }^{16}$ Cavendish needs this strong notion of an individual because Nature is necessarily composed out of an actual, and not merely a potential, infinity of (effective) parts such that each of these parts needs to exist independently as that part and not another part, while simultaneously existing as metaphysically dependent on other parts. Because of the requirement that there be an infinity of actual parts, each of the parts has to have an immanent criterion of identification qua that part. Insofar as we look at a local contingent set of parts, there are, of course, composite effective parts or composed creatures: a fly has wings, eyes, a stomach, antennae. But insofar as we treat these parts as parts of Nature (qua whole), just as the fly's stomach is an effective part of Nature, so are the fly and the antennae, and neither of these is more basic than the other. According to my reading, especially in her later works, Cavendish uses perception and self-knowledge to secure the interconnectedness and the individuality of Nature's parts that her view requires.

This reading entails a shift away from what the literature has so far seen as the relevant issues when it comes to perception and self-knowledge - that perception provides empirical knowledge of the actions of external parts of matter, while self-knowledge provides know-how and norms of behavior. Instead, I take perception and self-knowledge to be the metaphysical consequences of being a part of "the only matter."17 For Cavendish, the properties of matter are instantiated locally; thus, what it is for a part to be an individual, and what it is for a part to be connected to other parts, must be manifest in something immanent to that part. What does it look like for a part to be an individual? It looks like self-knowledge: for knowing matter, according to Cavendish, being an individual is the same thing as knowing you are an individual. And what does it look like for a part to be connected to other parts? It looks like perception of the surrounding parts.

According to the reading I set out in what follows, when Cavendish says that there would be no order in Nature without self-knowledge and perception, she should not be understood to be talking about the particular information required for appropriate action; rather, she is saying that the fundamental grounds for an orderly world are the individuality of parts and their connection with other parts. Without individuality or self-knowledge, there would be none of the distinctions between the things that our world contains. Without perception, nothing would take account of anything else - indeed, it is exactly

\begin{tabular}{ll}
\hline 16 & OEP 31. \\
17 & PPO 105.
\end{tabular}


on this basis that she rejects atomism..$^{18}$ Consequently, the central issue with self-knowledge and perception is, for Cavendish, one of fundamental metaphysics. ${ }^{19}$ Perception is just what it is for these parts to be interrelated and thus not separable from the body of Nature, while self-knowledge is just what it is for these parts to be individuals. Counterintuitively, perhaps, I suggest that bodies are, for Cavendish, simultaneously wholes and parts: a body is an individual whole, insofar as it is a self-knowing body; but at the same time, a body is not a whole, but a part insofar as it perceives. According to this reading, it is indeed true that, without self-knowledge and perception, matter would "run" into confusion. Without self-knowledge, all effective and constitutive parts "would be alike," and this part would be that part. ${ }^{20}$ And without perception, the parts of Nature would not be parts of the same Nature. Parts have to be perceptive because they are parts of matter, and they have to be self-knowing because each part is this part and not another. This, in not-so-small a nutshell, is the argument I set out below.

Cavendish favors reason over senses as a guide to establishing the principles of natural philosophy. Consequently, her overall strategy is to establish a set of principles, to deduce their implications and thus determine what is possible and what impossible, and then to provide natural-philosophical accounts of a variety of phenomena based on these principles. She calls these principles "grounds," and takes infinite, self-moving Matter and its properties to be the fundamental ground. ${ }^{21}$ If something is a ground, it is a "prime," "principal," or fundamental cause. But, according to my interpretation of Cavendish's account, to be a fundamental cause is not just to be responsible for the initial production of the effect, but to be continuously responsible for the very existence of that effect, such that Matter as fundamental cause is that from which everything else (material) derives its existence. Cavendish's employment of

18 E.g., PPO XX-Xxi; OEP 129, 168-169.

19 According to my reading, then, the issue of the appropriateness of particular actions is to be addressed elsewhere; my hypothesis is that the so-called appropriateness of response is accounted for by the sympathies and antipathies of bodies. Perception is just that by which bodies are related, on the basis of which they can sympathetically or antipathetically move. For instance, Cavendish accounts for human passions and emotions in terms of more or less sympathy; see GNP 72-73.

$20 \quad$ OEP 30.

21 PL 5. Cavendish tends to use "ground" and "principle" interchangeably. 
grounding relations is intricate, and does not stop with Matter as a fundamental ground. She also gives an account of the grounding relations that exist between the various properties of matter. I show here that these grounding relations are relations of metaphysical priority, in that they involve establishing what depends on what for its existence. ${ }^{22}$

Repeatedly, Cavendish claims that parts are grounded in matter, actions in self-motion, and perceptions in self-knowledge. ${ }^{23}$ This is so because the parts of matter are precisely parts of matter, particular actions of material bodies cannot exist without self-motion to produce them, and, she claims, perceptions cannot exist without self-knowledge. The grounded cannot exist without that which grounds it. ${ }^{24}$ Establishing what grounds what just is establishing what depends on what for its existence, and what is and is not self-subsistent. Thus, Cavendish claims:

though action or motion depends upon matter, yet matter does not depend upon motion, as being able to subsist without it: and though perception depends upon self-knowledge, yet self-knowledge does not depend upon perception: Nevertheless, wheresoever is perception, there is also self-knowledge; by reason, that wheresoever there is an effect in act or being, there is also its cause. ${ }^{25}$

So, matter can subsist without motion, but motion cannot subsist without matter, and self-knowledge can subsist without perception, while perception cannot subsist without self-knowledge. This is Cavendish's ground-grounded model: the ground is metaphysically prior to the grounded; it is not temporally prior, but existentially prior, such that the grounded derives its being from the ground. In the passage just quoted, however, Cavendish smuggles in a relation of causal dependency. She claims that the existence of an effect entails

22 Cavendish's claims about grounds have not yet been brought into focus in the scholarship. A notable exception is Alison Peterman, "Margaret Cavendish on Motion and Mereology," Journal of the History of Philosophy, 57 (2019), 471-499. Peterman discusses the centrality of mereological relations for Cavendish's account of motion, and in doing so notes that Cavendish conflates metaphysical and causal dependency and therefore does not have a robust account of grounding relations. My position is that insofar as Cavendish establishes relations of metaphysical priority, she does indeed have a workable notion of ground; whether Cavendishian grounding is distinct from Cavendishian causation is a separate issue.

23 See, e.g., OEP 138, 161, 156.

24 OEP 155. The metaphysical dependency is reiterated at OEP 156: "for were there not selfknowledge, there could not be perception."

25 OEP 165. For similar claims, see oEP 138, 155-157, 161, 163, 166-167, 171, 176, 191. 
the existence of its cause (i.e., a version of the principle of sufficient reason). But the dependency at stake is metaphysical, as it is not concerned with the production of the effect or why the effect is produced, but rather with the existence of the effect. It is true that Cavendish does not make an explicit distinction between causal and metaphysical dependency, but what she is interested in is the latter, albeit disguised as the former: she is interested in establishing the sources of the being of the grounded and not the manner of, or the reasons for, its production.

According to Cavendish, although self-knowledge is the fundamental cause (in Cavendish's sense) of perception, self-knowledge is not sufficient for perception to occur, which is why she claims that it is self-motion that provides the "occasion" for perception. ${ }^{26}$ The distinction between fundamental cause and occasion is central to Cavendish's account of inter-part activity: if I throw a ball, my act of throwing is the occasion triggering the ball's motion, while the ball is the cause of its own motion. ${ }^{27}$ Similarly, when I perceive the ball flying through the air, the ball provides the occasion for my perception, but my own self-knowledge is the cause of that perception - it is my self-knowledge that produces and sustains the existence of the perception. Self-motion occasions perception in that the self-motion of external bodies is what brings about the changes in them that provide the occasions for perception, whereas selfknowledge is the fundamental cause because it is what a perception derives its being from. ${ }^{28} \mathrm{~A}$ world without self-knowledge is necessarily a world without perception. Self-motion brings about perception in parts of matter that are already self-knowing. But if self-motion is absent, then perception is not brought about, and this is why Cavendish denies perception to the inanimate parts of matter. ${ }^{29}$ It is precisely because perception is grounded in self-knowledge and occasioned by self-motion that Cavendish unproblematically claims that there are two kinds of perception: the rational perception and the sensitive

$26 \quad$ Ibid., 176 (see also ibid., 155).

27 See, e.g., PL 97-100. On Cavendish's occasional causation, see O'Neill, "Introduction," xxxii-xxxv; Eileen O'Neill, "Margaret Cavendish, Stoic Antecedent Causes and Early Modern Occasional Causes," Revue philosophique de la France et de l'étranger, 3 (2013), 311326; Detlefsen, "Atomism, Monism, and Causation," eadem, "Reason and Freedom"; Boyle, The Well-Ordered Universe, esp. ch. 4. For a contrasting view, see David Cunning, Cavendish: Arguments of the Philosophers (London, 2016), 155-159.

OEP 176: "In short, self-knowledge is the fundamental cause of perception; but self-motion the occasional cause. Just like matter and self-motion, are the causes of all natural figures; for, though perception could not be without self-knowledge, yet were there no selfmotion, there would be no variety of figures, and consequently, not exterior objects to be perceived."

See, for instance, OEP 39, 157, 192 and GNP 7-8. 
perception. Since rational and sensitive parts are different parts and will consequently bring about different kinds of effects, each has its own perception. What matters is that all effective parts have rational and sensitive perceptions, including, e.g., rocks, even if humans do not have access to rock-reason. ${ }^{30}$

\section{3}

From Ignorance and Perception to Parts and Relations

We have seen that self-knowledge is the fundamental cause of perception, while self-motion is its occasional cause. According to Cavendish's account, perception between parts has a flipside: ignorance between parts. Actions or motions, for Cavendish, entail compositions or divisions of parts. ${ }^{31}$ When parts compose to other parts, parts are in perceptive relations, and when parts divide from other parts, ignorance follows.

In her response to skepticism, Cavendish makes the point thus:

[skeptics] are, in my opinion, in the right way, as far as their meaning is, that not any particular creature can know the infinite parts of nature; for nature having both a divisible and compoundable sense and reason, causes ignorance, as well as knowledge, amongst particulars. ${ }^{32}$

On the basis of her matter-theoretical commitments (i.e., because composition entails division), Cavendish defends a version of moderated skepticism prompted by the impossibility of eliminating ignorance from Nature. A composition of parts is instantiated at any given part as perception, and the division of parts as ignorance: "as a union or combination of parts makes knowledge, so a division or separation of parts, makes ignorance."33 It bears repeating that, for Cavendish, animal perception is a (derivative) kind of

30 E.g., PL 19; GNP 9, OEP 47. Often when Cavendish talks about rational perception, she seems to have in view something like inferential knowledge. For instance, at OEP 101: "if we desire to have some knowledge of the degrees of some sorts of heat or cold, my opinion is, that we may more easily attain to it by the help of rational perception, than by a sensitive inspection of artificial weather glasses, or the like."

OEP 163, 192; PPO: 76. On the composition and division of parts, see Peterman, "Margaret Cavendish on Motion and Mereology," and Shaheen, "Part of Nature and Division in Margaret Cavendish's Materialism."

$32 \quad$ OEP 214

33 OEP 20. In the GNP Cavendish makes a similar point, but more explicitly treats compositions as acquaintances or associations, thus making it even clearer that perceptive knowledges presuppose direct connection between parts. 
perception, and not her model of perception as such. Different things perceive in different ways, but, at root, her account is that to perceive just is to be connected with a part or parts: it is to be composed with, or acquainted with, that part or those parts. Likewise, to be ignorant of a part is to be divided from it. ${ }^{34}$

Cavendish's claim that "perception presupposes ignorance" is not metaphorical, but a necessary element in her material account of perception. If perception is a composition of parts, it works by relating parts to parts. Crucially, for Cavendish, relations (of any sort) are only possible between parts. A part of one whole cannot interact with a different whole because any interaction with a whole qua whole would be an interaction with an undividable. But an undividable whole is necessarily immaterial, by Cavendish's account, since she holds the classical, Euclidean position that to be material is to have parts. Following the same line of argument, a relation between a one-whole with another-whole is impossible. Similarly, while any given part can relate to one part or some parts of a whole, it cannot relate to all parts of a whole because that would either entail that a finite part relate to an infinite number of parts, which is impossible per the finiteness of the parts, or that that material whole qua whole has a determined number of parts, which is not possible since each part of that whole is material and therefore dividable. ${ }^{35}$ Necessarily, then, finite parts relate to finite parts.

If there is an oak tree in front of you, and you perceive it, each of your sensory organs, by its proper motions, patterns out some of the parts of the oak, while not patterning out others: your eye patterns out its height, thickness, color, etc., while your nose patterns out the scent, and so on. Furthermore, the eye patterns out only some of parts of the oak (the parts you can see); in doing

34 This is of course restricted to what Cavendish calls perceptive knowledges: i.e., situations in which the exterior object (or an exterior part) is present. The knowledge here is the knowledge in perception; it is not the accumulation of empirical data. In animal perception (at least), there are traces of former compositions internally stored via memory and imagination via the rational parts, which perceived the sensible parts perceiving the exterior object and thus patterned it out as well. Cavendish does not exclude a priori that the parts of non-animal creatures, say a stone, do not also store such traces of former compositions with other parts. After all, a stone is eroded by the rain. I want to thank the editor of this journal for raising my attention to this point.

Considerations about the impossibility of (causal) interactions between wholes and wholes, and between parts and wholes play into Cavendish's arguments about why materials and immaterials cannot interact. To be material is to have parts. Consequently, what is immaterial must necessarily not have parts and thus be an indivisible. At OEP 89 Cavendish uses such considerations to argue why finite parts of Nature cannot interact with God. Similarly, at PL 59, she tacitly uses these considerations to establish why we cannot justifiably claim that sense and reason are only properties of some creatures, or only of some parts of Nature; used also against atomism at OEP 262. 
so, the perceived parts are perceptually divided from the other (unseen) parts of the oak. If you walk around to the other side of the tree, to see the parts you missed at first, you will be involved in a new perceptual composition and division, and your perceptual knowledge of the oak will still be necessarily incomplete. ${ }^{36}$

Perceptual ignorance is a necessary corollary of perception and is not merely dispelled by an increase of perceptive knowledge (through cumulative acquaintance with more parts), because ignorance is not, for Cavendish, just an epistemological concept flagging some absence of perceptual knowledge. Ignorance is ontological, and is just as real and concrete as perception: both are effects of the same motion. We might think of ignorance as a difference maker in perceptive knowledge: without it, no particular knowledge could be picked out as being the knowledge about that particular rather than about any other particular. There could be no particular perceptive knowledge without ignorance, just as, without division, there could be no particular parts. When responding to More's views on the indivisible nature of the mind, Cavendish claims that:

for if there were not ignorance through the division of Parts, every man and other creatures would know alike; there is no better proof, that matter, or any particular creature in nature is not governed by a created Immaterial Spirit, then that knowledge is in parts: for the hand doth not know what pain the head feels, which certainly it would do, if the mind were not dividable into parts, but an individable substance. ${ }^{37}$

If the mind were an indivisible, or what Cavendish calls "individable," then there could not be a distinction between the various kinds of cognitive processes, nor would there be a difference between how the hand senses and how the head feels pain because, being indivisible, the mind could not contain knowledge of particular content, because knowledge itself would have to be indivisible. Everything would collapse into non-distinctness. What individuates what one creature knows is not just what is peculiar to that creature's perceptive knowledges, but also what that creature is separated from, or ignorant

\footnotetext{
$36 \quad$ Memory will help build up a more complete idea - what Cavendish would call a conception - of the tree, but this is a separate issue from that of perceptive knowledge; see n. 4. 
of. Consequently, worlds of universal perceptive knowledge or of absolute ignorance end up inconceivable within Cavendish's philosophy. ${ }^{38}$

It is for these reasons that perception is purely an "external knowledge," "a sort of knowledge that hath reference to Objects; that is, Some Parts to know other Parts." ${ }^{39}$ It is a part-to-part knowledge, and there is no perception without reference to other, external parts. ${ }^{40}$ Indeed, because of this part-to-part relationality, and its manifestation in the perception-ignorance binary, Cavendish explicitly denies the possibility of "interior self-perception" (and selfignorance):

I do not mean, an interior or self-ignorance, which cannot be in nature, by reason every part and particle has self-knowledge; but, an exterior, that is, an ignorance of foreign parts, figures or actions, although they be parts of one composed figure; for, the parts of the hand do not know the parts of the stomach, and their actions. Neither do I mean an interior selfperception, which can neither be in nature, because perception presupposes ignorance; and if there cannot be a self-ignorance, there can neither be a self-perception. ${ }^{41}$

A part cannot have self-perception, because perception and ignorance are effected by the same act, so that, if a part had self-perception, it would necessarily have self-ignorance. But self-ignorance is impossible in Nature (and its parts), because self-ignorance would presuppose a division from oneself, and that would be contradictory. Thus, perception contrasts with self-knowledge in both its exteriority and its incompleteness. If there were only one thing in the universe, it would have self-knowledge but could have no perception. Perception and ignorance only come about once we introduce something external once we introduce other parts. While self-knowledge exists entirely within each and every part, perception and ignorance, being predicated on what the part lacks, have a dependency outside the part, in its relation to other parts. This, I take it, is what the occasional causation of perception consists in. In this way, each part maintains relationality with other parts.

According to this reading, then, perception is what conserves the interdependence between parts. It is a relation of knowledge between parts; it is not strictly what one part knows about other parts. It is the perceptive relation of

38 Cavendish nowhere explicitly makes such a claim, but gets close to doing so in her discussion of skepticism in OEP, esp. 214.

39 GNP 8.

40 OEP 165.

$41 \quad$ OEP 163. 
the parts that allows each part within the relation to be the relatum it is (and correspondingly to act as it does). The claim is that parts of nature are perceptive insofar as they are part of a perceptual relation. Cavendish holds that the parts of nature are necessarily interconnected: as instantiated at each part, this is just perception.

\section{Self-knowledge}

\subsection{Self-knowledge and Self-motion}

Perceptive knowledge is exterior, because it involves relations. Self-knowledge does not: it is proper to each and every single body by itself: humans, stones, minerals, Nature herself, and all of her constitutive parts, including the inanimate parts of matter, are endowed with self-knowledge. ${ }^{42}$

That inanimate matter should have self-knowledge has struck many scholars as an odd position to hold. Boyle notes that, given Cavendish's commitment to the complete blending doctrine, it is hard to understand why she found it necessary to claim that inanimate parts have self-knowledge. ${ }^{43}$ Similarly, Michaelian points out that Cavendish defies expectations by attributing life and knowledge to inanimate matter as well as to self-moving matter. ${ }^{44}$ But it is only odd for inanimate matter to be self-knowing if one assumes that self-knowledge is somehow presupposed by, dependent on, or in some other relevant way connected to, self-motion..$^{45}$ This assumption informs the current discussions around self-knowledge. Boyle suggests that Cavendish "derives the further claim that [parts of matter] also possess perception and knowledge" from taking rational and sensitive matter to be self-moving. ${ }^{46}$ For Michaelian, Cavendish "holds that self-knowledge somehow supervenes on self-motion or even that self-knowledge and self-motion ultimately are the same."47 This reading finds some support in Cavendish's earlier works, although it should be noted

42 OEP 138, 156; GNP 8.

43 Boyle, "Margaret Cavendish on Perception," 35, n. 11.

44 Michaelian, "Margaret Cavendish's Epistemology," 35.

45 For instance, one might make the (traditional but non-Cavendishian) assumption that only what is animate is alive, alongside the assumption (which Cavendish does endorse) that only what is alive can have knowledge.

46 Boyle, "Margaret Cavendish on Perception," 439.

47 Michaelian, "Margaret Cavendish's Epistemology," 48, n. 36. Given Cavendish's stringent commitments to materialism and her rejection of all sorts of abstractions, including modes, treating self-knowledge as a supervenient or an emergent property appears, to my mind, untenable. Supervenient or emergent properties would have looked ontologically suspect to Cavendish. 
that the concept of self-knowledge is not present in those early works, being introduced in OEP. The concept pervades her mature works, however, to the point of claiming that all parts of Nature, including the inanimate, must "of necessity" be self-knowing. ${ }^{48}$ In OEP, Cavendish separates self-knowledge from self-motion:

life and knowledge did [in] no ways depend upon self-motion: for, had nature no motion at all, yet might she have life and knowledge; so that self-motion is not the cause of life and knowledge. ${ }^{49}$

Furthermore, Cavendish takes self-knowledge and self-motion to be independent grounds: self-knowledge is the ground of all particular knowledge, and self-motion is the ground of all particular actions. ${ }^{50}$ Thus, while perceptive knowledge has a dependence (an occasional dependence) on self-motion, knowledge in general does not, and neither does self-knowledge in particular.

Since self-knowledge and self-motion can be and are independent of each other, and since the cause of any action is self-motion, we may conclude that self-knowledge is not, on Cavendish's account, an action. If self-knowledge does not, in any way, depend on self-motion, and is not an action, then Cavendish's claim that inanimate matter has self-knowledge is not at all odd: selfmotion is simply irrelevant to self-knowledge. This does not, yet, however, tell us what self-knowledge actually is. In the next subsection, I consider - and give reasons for rejecting - the consensus view in the literature, before, in the subsequent subsection, giving a reading of self-knowledge as knowledge of individuality.

\subsection{Self-knowledge as Know-how?}

In the literature, Cavendish's account of self-knowledge has tended to be tied to two correlated problems: causation and order. For how can we explain any sort of regularity in interaction if both causal transfer and (divine) occasionalism are denied? Cavendish's own version of occasional causation allows for

48 GNP 12.

49 OEP 39. Alongside self-knowledge, especially in OEP and GNP, Cavendish claims that life is basic to nature such that even if matter were not self-moving it would still be living. Of course, if this is the case, the implication is that Cavendish imposes a shift in what being alive is all about. One possibility is that, at least in some of her later works, Cavendish takes life to be synonymous with natural existence such that everything naturally existing is alive. But more argument would be needed to substantiate this claim, and formulating such an argument goes beyond the goal of this paper. OEP 161. 
self-motions to be occasioned by other parts, but it does not seem to have the resources to explain why behavior has any regularity: if I throw a ball, my hand occasions the ball to move by its own self-motion, but the ball does not just randomly fly up in the air, nor does it move parallel to my hand, or move backwards, and so on. Rather, the ball follows a trajectory upwards for a while and then towards the ground. And this behavior is more or less the same however many times I throw the ball. On a mechanical motion-transfer account, the behavior is explained by the motions or pressure transferred from the surrounding bodies to the ball. Without transfer, it seems reasonable to infer that, if bodies behave regularly, they must know what they are doing and what they ought to be doing. ${ }^{51}$ How the ball knows which motion to produce remains unexplained, and this is where, in the literature, self-knowledge is brought in to do the explanatory work.

For both Michaelian and Boyle, self-knowledge is knowledge of a part's current state and activity, along with an internal set of instructions on the basis of which a body responds to a given situation. ${ }^{52}$ On Boyle's reading, self-knowledge also includes norms of behavior, such that a body's response is normatively evaluated: a response is proper and ordered if it follows the norms, and improper and disordered if it does not. As the ultimate self-knower, then, Nature as a whole contains within itself knowledge of all the norms of all its parts, i.e., self-knowing Nature is a knower of all norms. ${ }^{53}$ For Boyle, these norms are divinely instituted as innate knowledge in each part. ${ }^{54}$ Michaelian does not explicitly discuss how a body gets its know-how: it could be the product of either statistical regularity or historical material traces of its figured corporeal motions. Broadly, all these can be described as elements of know-how. ${ }^{55}$ On the know-how reading, we get an over-inflated concept of self-knowledge which, I believe, Cavendish does not endorse. To show why, I discuss below some of the problems by which, I believe, self-knowledge as know-how is beset.

To begin with, the know-how reading does not explain why Cavendish insists on attributing self-knowledge to inanimate matter. ${ }^{56}$ If self-knowledge

$5^{1} \quad$ Note however that the ball's trajectory is not in fact one motion, and nor is it the result of one decision. The ball meets many occasions in its trajectory: the air, the wind, the light and so on. The trajectory of the ball is the result of a large number of corporeal motions and perceptive actions. It is by what Cavendish would call "art" (e.g., mixed mathematics) alone that we can treat the motion of the ball as one continuous and single motion. Michaelian, "Margaret Cavendish's Epistemology;" Boyle, The Well-Ordered Universe, ch. 4. Boyle agrees with Detlefsen and argues that bodies have the freedom to follow the norm or not.

54 Boyle, The Well-Ordered Universe, 104-114.

55 Michaelian calls it "knowledge-how" ("Margaret Cavendish's Epistemology," 46).

$5^{6} \quad$ As both Boyle and Michaelian are aware; see notes 43 and 44. 
consists in the instructions for action as occasioned by perceived motions, then we cannot make sense of the attribution of self-knowledge to inanimate matter itself. As discussed above, Michaelian and Boyle's solution is to treat the self-knowledge of inanimate parts as somehow "derivative of the life and knowledge of animate matter," but this directly violates Cavendish's often reiterated claim that all parts of nature, explicitly including the inanimate parts, are self-knowing. ${ }^{57}$ It also violates her dependency relations, wherein selfknowledge not only has no dependency on, but is more primitive than, selfmotion. ${ }^{58}$ It is for this reason that, on the knowledge-how reading, the self-knowledge of inanimate matter looks so incomprehensible: if something is constitutively incapable of action, why would Cavendish ascribe it knowledge of how to act?

On Michaelian's reading, self-knowledge is an interior type of knowledge, but it also includes "knowledge of external things that is not occasioned by the presence of those things." ${ }^{59}$ Such an account, again, gets a dependency relation upside-down: as we saw in section 2, self-knowledge is the ground of all particular knowledge, that is, all particular types of knowledge depend on selfknowledge, and not the other way around. ${ }^{60}$ Self-knowledge cannot stricto sensu be about particulars, since, as we have seen, particulars qua particulars entail perceptive knowledge. Similarly, Boyle claims that the first "component" of self-knowledge includes "a creature's knowledge of how it moves," in order to coordinate its actions with other parts. ${ }^{61}$ But this again violates the priority relations between self-knowledge and self-motion, along with the independence of the former from the latter. Additionally, at least on a flat-footed analysis, the know-how reading makes self-knowledge unavailable to Nature as a whole, since Nature as a whole has no external relations. If we take the point to be that Nature as a whole knows how all of its parts move, then not only do we run into the issue of whole-to-part relations, but it would also seem that the parts of Nature do not enjoy the kind of freedom they are supposed to ${ }^{62}$

The strength of Boyle's reading of self-knowledge is that it seems to accommodate, somewhat more successfully than Michaelian's, the properties of selfknowledge as "an interior, inherent, innate, and, as it were, a fixt being."63

57 Michaelian, "Margaret Cavendish's Epistemology," 35, n. 11. For the claim that all parts are self-knowing see e.g. OEP 156.

58 See section 2.

59 Michaelian, "Margaret Cavendish's Epistemology," 45.

6o OEP $138,161,176$.

$61 \quad$ Boyle, The Well-Ordered Universe, 105.

62 See Detlefsen, "Reason and Freedom." Of course, one option here is simply to deny that Cavendish has a libertarian account of the freedom of the parts of Nature.

63 OEP 176. 
Because, according to Boyle's account, self-knowledge contains the norms of behavior imposed by God on the parts of Nature at creation, these norms are innate and inherent, and are fixed because they cannot be changed. I assume that it is precisely this set of properties that informs Boyle's conclusion that there are natural norms in self-knowledge. But I am not convinced that we are obliged to read Cavendish's claims about the properties of self-knowledge as being guides to innate norms of behavior, for two reasons. First, accepting Boyle's suggestion entails contravening Cavendish's repeated claims that God should not be appealed to in natural philosophy and that God's nature and intentions are impossible to be known by any of matter's parts, as God is an immaterial substance. ${ }^{64}$ Secondly, we can make sense of self-knowledge's properties without having to appeal to norms of behavior, and without being subject to the problems they raise: self-knowledge is a fixed being because it is independent of self-motion and therefore does not change; it is innate because it is not acquired through interaction with other parts; it is inherent because it is proper to that part and to no other; and it is interior because it does not entail relation to other parts. Cavendish is clear that no part can lose or be divided from its own self-knowledge, because it is not the kind of thing that one can be divided from or be composed with. ${ }^{65}$

A final worry with the know-how reading is the explicit connection between self-knowledge and the alleged problem of order. The reading attempts to solve the mystery of what self-knowledge is by plugging it into the mystery of the regularity of Nature. Cavendish herself appears to allow for the connection:

If Nature were not Self-knowing, Self-living, and also Perceptive, she would run into Confusion: for, there could be neither Order, nor Method, in Ignorant motion; neither would there be distinct kinds or sorts of Creatures, nor such exact and methodical Varieties as there are: for, it is

64 Deborah Boyle and Karen Detlefsen are resolute in arguing that, despite her claims to the contrary, Cavendish does in fact allow for God to play a central role in her philosophy, as in their view God is ultimately responsible in Cavendish's system for the order we see in Nature. See Boyle, The Well-Ordered Universe, and Karen Detlefsen "Margaret Cavendish on the Relation between God and World," Philosophy Compass, 4 (2009), 421-438. It is true that especially in OEP and GNP, Cavendish does state, much more so than in some of her early works (PPO, for example), that we have knowledge of God's existence (e.g. OEP 8889), but I would argue that from the knowledge of these two facts one cannot extrapolate to knowledge of God's intentions or of God's plan and manner of work; because while knowledge of God's existence is explained by the fact that the existence of Nature entails the existence of its cause, i.e., God, God's manner of creation is not. There is no philosophical reason to claim that God created according to norms, as that would require some particular knowledge concerning God's manner of creation. OEP 20. 
impossible to make orderly and methodical Distinctions, or distinct Orders, by Chances. ${ }^{66}$

Many such passages can be found in all of Cavendish's writings. But I want to signpost here some reasons to be cautious of reading such passages as indicating a problem of the order between the effective parts. For one thing, Cavendish's concern here seems to be metaphysical, since it is concerned with fundamental principles, and addresses them through modality. Shifting from these metaphysical claims to a problem tracked in terms of the norms of behavior of particulars is not unproblematic: the behavior of particulars is grounded in the principles, and not the other way around. Cavendish is concerned, in this passage, with establishing what characterizes motion, and what allows for there to be distinctions in the world, as instantiated in the variety of creatures in the first place. I would suggest that we need not read this as a concern with the regular or the proper behaviour of these creatures. I would also suggest that this is usually the case when Cavendish worries about Nature running into confusion.

The overall claim of the passage is that if nature were not self-knowing, selfliving, and perceptive, it would have "ignorant motion," and such a motion would allow "neither order, nor method" nor "distinct kinds of creatures" or "methodical varieties." But why not? The possibility she entertains here is one in which Matter (or Nature) is endowed merely with the property of motion, but not with life or self-knowledge. If matter is self-moving but not self-knowing, then it also cannot be perceptive. The outcome is ignorant motion (associated here also with chance). Such ignorant motion is indeed not intelligent, but why should it be impossible for a non-intelligent motion to bring about order, distinctions between creatures, and variety? This is not an a posteriori claim about what we know from experience as to nature's variety and order. If it were, its conclusion would have to be counterfactual, but not counter-possible: it would be possible, but improbable for order to result from non-intelligent action, and Cavendish is very familiar with categorization as probable and improbable. ${ }^{67}$ My suggestion is that the impossibility is grounded in the nature of ignorant motion itself: on Cavendish's definition, ignorance entails division, and so purely ignorant motion, were it possible, would be division without composition, entailing the loss of the interconnection of parts. Without any connection between parts, order is indeed metaphysically impossible. I take it

$66 \quad$ GNP 7 .

67 See for instance PPO xx-xxi; GNP 285-287. For Cavendish's probabilistic epistemology, see Boyle "Perception, Self-knowledge, and Probable Opinion." 
that Cavendish's point, in passages like these, is not about the behaviour of particular parts, but about the conditions for the interconnection of parts.

The know-how reading is the dominant position in the literature. But, for the reasons given above, self-knowledge cannot be characterized by knowhow. This is not to say that the parts of Nature cannot have know-how at all - it could well be one of the derivative particular types of knowledge; it just cannot be what fundamental self-knowledge consists in.

\subsection{Identity and Self-knowledge}

According to Cavendish's account, all matter, in "every part and particle," has self-knowledge, and has it necessarily such that "wheresoever is matter, there is life and self-knowledge." ${ }^{\prime 6}$ But why would Cavendish insist on attributing self-knowledge to each and every single part? One might suggest that she does so because Nature as a whole has self-knowledge, and, since parts are nothing but parts of Nature, they consequently have self-knowledge: the self-knowledge of the parts is grounded in the self-knowledge of the whole. But this simply defers the question: why does Cavendish attribute self-knowledge to matter, qua whole or part, at all? As we saw in the previous subsection, the standard answer is that Cavendish posits a self-knowing nature in order to explain the variety and order of nature. But variety and order are effects of Matter's actions, and, as we have seen, self-knowledge, being internal and complete, cannot have anything to do with actions, which are external and incomplete (cf. ignorance). Furthermore, the actions of Matter require self-motion, and, as already shown, Matter would have had self-knowledge even if it did not have self-motion. What, then, is left to self-knowledge? In addressing the question of whether attributing self-knowledge to inanimate matter entails that it "would also be sensible of itself," Cavendish answers:

Self-knowledge is so far sensible of itself, that it knows itself; and therefore the inanimate part of matter being self-knowing, may be sensible of its own self-knowledge; but yet it is not such a sense as self-moving matter has, that is, a perceptive sense. ${ }^{69}$

This is the most explicit statement Cavendish gives as to the content of pure self-knowledge: whatever has self-knowledge knows itself, and possibly also has second-order knowledge of that self-knowledge. Each body knows

68 OEP 20.

69 OEP 156 (my emphasis). Note that Cavendish is careful to point out that self-sensibility is not the same kind of thing as perceptive sensation. 
(intimately and irreducibly) that it is that body, and it could possibly also be aware of this knowledge. As an account of self-knowledge, this might sound underwhelming, but my proposal here is to take this claim quite literally: selfknowledge is knowledge that something has of itself as itself; self-knowledge just is what it is for a part to identify itself as itself. ${ }^{70}$ That self-identification is minimal: nowhere does Cavendish suggest that self-knowledge requires anything propositional, or some sort of knowledge-how, or of norms. This is why inanimate matter has self-knowledge: it is just as capable of identifying itself to itself as animate matter is. But this is also why inanimate matter is necessarily self-knowing: because the fundamental properties of matter are instantiated locally, each part must have an immanent source of its fundamental identity. Thus, self-knowledge is what gives identity to a thing.

\subsection{Self-knowledge and Wholes; Perception and Parts}

Cavendish does have another account of individuation, grounded in perception rather than self-knowledge: she describes the parts of Nature as being "discerned from each other" by their "limited and circumscribed" (and therefore finite) figures, which result out of "corporeal motions"; insofar as they are parts, they are "not single figures, for they are all joined in one body, and are parts of the one infinite whole, which is nature."71 That is, qua part, a part is identified relationally. This is precisely how parts are picked out in her account of perception. Since all perception is only partial, however, the individual is necessarily only imperfectly delimited on the perception model. This is to be expected: since perception works part-to-part, the individual picked out is a part rather than a whole. For Cavendish, then, no external knowledge of an individual is complete knowledge of that individual. ${ }^{72}$ By contrast, the self-knowledge model provides complete knowledge qua identity of a given individual. Each individual is an irreducible self-knower. After all, "nothing can have a knowledge of itself, otherwise than what it is."73

70 Thus, I agree with Michaelian to the extent that we both take self-knowledge to be a theoretical primitive, but for a different reason. Self-knowledge is a primitive, because it is the ground of all particular knowledge, and because qua ground it has metaphysical priority, it cannot be in fact explained by appealing to something else. Self-knowledge is needed because the parts of nature are, and have to be, truly distinct: see Michaelian, "Margaret Cavendish's Epistemology," 45. OEP 31. Karen Detlefsen argues for an account of physical individuals as figured portions of matter whose stability is maintained by the sympathy between parts; see Detlefsen "Atomism, Monism, and Causation."

72 OEP 141.

73 OEP 166 
According to my reading, then, through perception, a thing is a part, while, through its own self-knowledge, it is a whole. Thus, any given bit of matter is ontologically both a whole and a part, with the switch being made relative to the kind of knowledge through which it is picked out. ${ }^{74}$ In this way, the parts of Nature are truly parts of Nature (in their interconnection, instantiated in their perception), but also truly wholes (in their identification, instantiated in their self-knowledge): it is through the switch between perception and self-knowledge that Cavendish gets to secure both identity and interconnection in her ontology.

\section{Conclusion}

An individual is the individual that it is insofar as it is self-knowing. As identified through its self-knowledge, it is a complete whole, and it does not relate to anything other than itself. This identification is what self-knowledge amounts to. At the same time, the individual is also a part, insofar as it perceives and is perceived. In other words, an individual does not enter into interactions as a whole but as a part, even though, in itself, through its self-knowledge, it still remains a whole. The major advantage of interpreting Cavendish's claims to self-knowledge and to perception in this way is that it gives her the philosophical resources to defend a metaphysical account of what an individual is, when that individual can only be a part of Nature. It also makes sense of Cavendish's attribution of knowledge to inanimate parts. Cavendishian Matter is selfknowing and perceptive just insofar as it maintains both the individuality of each part and the interconnection between parts: as instantiated in each part, individuality is self-knowledge, and interconnection is perception.

I have made the case that this is how we should understand Cavendish's account of perception without relying on animal perception as a (misleading) model, that is, without inverting the dependency relations. Cavendish thus provides an account of self-knowledge and perception as metaphysical notions that allow each body to be simultaneously a whole and a relational part.

74 This somewhat parallels Cavendish's theory of complete blending: seen from the perspective of the constitution of matter and of matter's effects, the inanimate, the rational and the sensitive are completely blended and "constitute but one body, because of their close and inseparable conjunction and commixture; nevertheless, they are several parts, (for one part is not another part)" (OEP 127). 